\title{
Solid papillary carcinoma with reverse polarity of the breast harbors specific morphologic, immunohistochemical and molecular profile in comparison with other benign or malignant papillary lesions of the breast: a comparative study of 9 additional cases
}

\author{
Nadjla Alsadoun ${ }^{1} \cdot$ Gaëtan MacGrogan ${ }^{2} \cdot{\text { Caroline } \text { Truntzer }^{1} \cdot \text { Magali Lacroix-Triki }}^{3} \cdot$ Isabelle Bedgedjian $^{4}$. \\ Marie-Hélène Koeb ${ }^{5} \cdot$ Elsy El Alam ${ }^{6} \cdot$ Dan Medioni $^{7} \cdot$ Michel Parent $^{8} \cdot$ Pascal Wuithier $^{9} \cdot$ Isabelle Robert $^{10}$. \\ Romain Boidot ${ }^{1} \cdot$ Laurent Arnould $^{1}$
}

Received: 24 July 2017 / Revised: 3 February 2018 / Accepted: 4 February 2018 / Published online: 21 May 2018

(c) United States \& Canadian Academy of Pathology 2018

\begin{abstract}
Solid papillary carcinoma with reverse polarity is a rare breast cancer of favorable prognosis that can be difficult to diagnose. We report here nine additional cases of this tumor, and we describe its morphologic, immunohistochemical and molecular profile in comparison to other types of papillary and micropapillary lesions of the breast that are intraductal papilloma with usual ductal hyperplasia, encapsulated papillary carcinoma, solid papillary carcinoma and invasive micropapillary carcinoma. We studied nine cases of this special papillary tumor and six of each other types mentioned above. We found that solid papillary carcinoma with reverse polarity harbor specific morphologic features as cuboid or tall cells with abundant eosinophilic cytoplasms located at the basal pole giving the impression of reverse nuclear polarity. Nuclei were sometimes grooved. Immunohistochemistry demonstrated the lack of myoepithelial cells, as in encapsulated papillary carcinoma and solid papillary carcinoma, questioning their invasive nature. Seven of nine solid papillary carcinoma with reverse polarity showed a low Ki67 proliferative index (Ki67 <5\%). They showed expression of CK5/6 as in intraductal papilloma with usual ductal hyperplasia. They showed expression of calretinin and a low or lack of hormonal receptor (HR) expression that were not observed in other breast tumors studied. By whole-exome analysis, seven of nine solid papillary carcinomas with reverse polarity (78\%) harbored a hotspot mutation in IDH2 (R172) that was totally absent in other groups. Six of nine tumors (67\%) also harbored PRUNE2 mutation, including the two IDH2 wild-type cases. We also demonstrated for the first time in this breast tumor, immunostaining with a specific antibody IDH1/2 mutant R132/R172 (7/9) that can highlight IDH2 mutation. Moreover, transcriptomic analysis showed that proteoglycan pathway was significantly enriched. Our findings support the fact that solid papillary carcinoma with reverse polarity is a singular breast neoplasm that can be distinguished from other papillary breast tumors.
\end{abstract}

Nadjla Alsadoun

nadjla.alsadoun@gmail.com

1 Département de Biologie et Pathologie des Tumeurs, Centre Georges-François Leclerc - Unicancer, 1 rue Professeur Marion, 21000 Dijon, France

2 Département de Biopathologie, Institut Bergonié, 229 cours de 1' Argonne, 33076 Bordeaux, France

3 Département de Pathologie, Institut Gustave Roussy, 114 rue Edouard Vaillant, 94805 Villejuif, France

4 Service d'Anatomie et Cytologie Pathologiques, Centre Hospitalier Universitaire de Besançon, 25030 Besançon Cedex, France
Cypath Lyon, 201 route de Genas, 69100 Villeurbanne, France

6 Département de Pathologie, Institut Curie, Saint Cloud, 35 rue Dailly, 92210 Saint Cloud, France

7 Medipath Cannes-Antibes-Grasse, 80 allée des ormes, 06250 Mougins, France

8 Pathologie Nord Unilabs, 60 boulevard Jean Baptiste Lebas, 59000 Lille, France

9 Centre de Pathologie, 13 rue Carnot, 65000 Tarbes, France

10 Atalante Pathologie, 10 rue J-Louis Bertrand -BP11633, 35016 Rennes cedex, France 


\section{Introduction}

Papillary lesions of the breast constitute a heterogeneous group of neoplasms including benign, atypical and malignant lesions (in situ or invasive). They represent about 5\% of all breast lesions [1]. They are characterized by a specific architecture composed of papillae, centered by fibrovascular cores and lined by epithelial cells with or without underlying myoepithelial cells. Some of them are made of micropapillae that are devoid of fibrovascular cores [2]. These features are usually well recognized. Nevertheless, evaluation of papillary lesions remains problematic for most pathologists, because there are overlap features between these different lesions. Thereby, to separate these lesions with different prognoses, immunohistochemistry (IHC) is very useful or even essential. These tumors also display various genetic alterations, but they are till now not commonly used in the routine practice.

In 2003, Eusebi et al. [3] first reported five cases of a very rare breast papillary lesion, initially named breast tumor resembling the tall cell variant of papillary thyroid carcinoma because of its resemblance with papillary thyroid carcinoma. None of these five cases expressed thyroidspecific markers. Thanks to molecular studies that followed, it has been proven that these tumors were definitely not related to thyroid carcinoma, especially with lack of $B R A F$ or RET alterations [4]. Since 2003, 37 additional cases of this rare breast tumor were reported [5-12]. These tumors harbor specific histological and immunohistochemical features [2] and often consist of circumscribed solid nodules of epithelial cells arranged in nests or papillae. Epithelial cells are characterized by eosinophilic, cuboidal or tall cytoplasms, with altered nuclear polarity and nuclear grooves. The lack of myoepithelial cells between fibrovascular cores and epithelial cells is another distinctive feature. These tumors are considered as low-grade invasive carcinomas because lymph node invasion has been reported in only four cases [5, 6, 12] with one associated to bone metastasis [6]. Recently, Chiang et al. [10] analyzed a series of 13 of this exceptional papillary breast tumor at the molecular level and identified a somatic mutation of the IDH2 (isocitrate dehydrogenase 2) gene at R172 in 10 of them. They also described a concomitant mutation in the PIK3CA gene in eight of these ten tumors, and one TET2 gene mutation associated with a PIK3CA gene mutation in a wild-type $I D H 2$ case. They proposed to name this entity solid papillary carcinoma with reverse polarity.

The purpose of the present study is to report nine additional cases of this tumor and to focus on their macroscopic, microscopic and immunophenotypic features in comparison with two types of frequent papillary lesions and one type of micropapillary lesion of the breast that are encountered in current practice. These differential diagnoses studied were intraductal papilloma with usual ductal hyperplasia, encapsulated papillary carcinoma, solid papillary carcinoma and invasive micropapillary carcinoma.

We also analyzed all these breast tumors in terms of genetic mutations and transcriptomic signatures by using next-generation sequencing to confirm the specific mutations previously described $[9,10]$ and to search for other specific genetic alterations.

\section{Materials and methods}

\section{Cases}

Nine tumors diagnosed as solid papillary carcinoma with reverse polarity were retrieved from the consultation cases files of three authors (LA, GM and ML-T). These cases (cases 1 to 9) came from different laboratories in France, between 2008 and 2017. Slides were reviewed, tumors were evaluated for their morphologic appearance and cases were included in the study.

To compare, six cases of invasive micropapillary carcinoma (10 to 15$)$, of encapsulated papillary carcinoma (16 to 22), of intraductal papilloma with usual ductal hyperplasia (22 to 27) and of solid papillary carcinoma (28 to 33) were randomly collected from databases of the Centre GeorgeFrancois Leclerc pathology departments and were included in the study.

Data on patient age at the time of diagnosis, breast side, gross inspection, tumor size, lymph node status, lymphovascular invasion, patients' management, recurrence and follow-up were collected for all these 33 breast lesions.

The samples from the tumor archives of each participating laboratory were centralized in the Centre GeorgesFrançois Leclerc for which the French authorities authorized for scientific research (AC-2014-2260). The study was approved by the ethical and scientific committee of the Centre Georges-François Leclerc.

\section{Morphology and immunochemistry}

Immunohistochemical analysis was performed using an automatic stainer (Ventana Benchmark XT system ${ }^{\circledR}$, Roche $^{\mathrm{TM}}$ ) with UltraView Universal DAB detection for each antibody. Antibodies used were: cytokeratin (CK) 5/6 and 7 (CK5/6, CK7), p63, calponin, estrogen receptor (ER), progesterone receptor (PR), HER2, androgen receptor (AR), gross cystic disease fluid protein-15 (GCDFP-15), TTF1, Calretinin, Ki67, chromogranin A and synaptophysin.

Due to the recent publication by Chiang et al. [10], a complementary immunohistochemical test was performed in the present series, using IDH1/2 mutant (R132/R172) antibody (clone MsMAb-1, Merck Millipore) which is a 
Table 1 Details of antibodies used in the current study

\begin{tabular}{llllllll}
\hline Antibodies & Clone & Dilution & Antigen retrieval & Kit detection & Manufacturer & Automatic stainer & Staining pattern \\
\hline CK5/6 & D5/16B4 & $1 / 25 \mathrm{e}$ & $\mathrm{Ph} 8,4$ & Ultraview DAB & Life technologie & Benchmark XT & Cytoplasmic \\
CK7 & OV/TL-12/30 & $1 / 75 \mathrm{e}$ & $\mathrm{Ph} 8,4$ & Ultraview DAB & Agilent (Dako) & Benchmark XT & Cytoplasmic \\
p63 & 4A4 & Prediluted & $\mathrm{Ph} 8,4$ & Ultraview DAB & Roche & Benchmark XT & Nuclear \\
Calponin & CALP & $1 / 500 \mathrm{e}$ & $\mathrm{Ph} 6$ & Ultraview DAB & Agilent (Dako) & Benchmark XT & Cytoplasmic \\
ER & SP1 & Prediluted & $\mathrm{Ph} 8,4$ & Ultraview DAB & Roche (Ventana) & Benchmark XT & Nuclear \\
PR & 1E 2 & Prediluted & $\mathrm{Ph} 8,4$ & Ultraview DAB & Roche (Ventana) & Benchmark XT & Nuclear \\
AR & SP107 & Prediluted & $\mathrm{Ph} 8,4$ & Ultraview DAB & Roche (Ventana) & Benchmark XT & Nuclear \\
TTF1 & 8G7G3/1 & $1 / 200 \mathrm{e}$ & $\mathrm{Ph} 8,4$ & Ultraview DAB & Microm & Benchmark XT & Nuclear \\
Calretinin & PAD: DC8 & $1 / 50 \mathrm{e}$ & $\mathrm{Ph} 8,4$ & Ultraview DAB & Life technologie & Benchmark XT & Cytoplasmic \\
GCDFP-15 & D6 & $1 / 60 \mathrm{e}$ & $\mathrm{Ph} 6$ & Ultraview DAB & Eurogentech & Benchmark XT & Cytoplasmic \\
Ki67 & MIB1 & $1 / 50 \mathrm{e}$ & $\mathrm{Ph} 8,4$ & Ultraview DAB & Agilent & Benchmark XT & Nuclear \\
IDH2 & MsMab-1 & $1 / 50 \mathrm{e}$ & $\mathrm{Ph} 8,4$ & Ultraview DAB & Merck Millipore & Benchmark XT & Cytoplasmic \\
Chromogranin A & LK2H10 & $1 / 200 \mathrm{e}$ & $\mathrm{None}$ & Ultraview DAB & Diagomics & Benchmark XT & Cytoplasmic \\
Synaptophysin & SP11 & $1 / 100 \mathrm{e}$ & $\mathrm{Ph} 8,4$ & Ultraview DAB & Clinisciences DBS & Benchmark XT & Cytoplasmic \\
HER2 & 4B5 & Prediluted & $\mathrm{Ph} 8,4$ & Ultraview DAB & Roche (Ventana) & Benchmark XT & Membranous \\
\hline
\end{tabular}

$A R$ androgen receptor, $C K$ cytokeratin, $E R$ estrogen receptor, GCDFP-15 gross cystic disease fluid protein-15, HER2 human epidermal growth factor receptor $2, I D H 2$ isocitrate dehydrogenase 2, $P R$ progesterone receptor, TTF1 thyroid transcription factor 1

specific antibody able to recognize the IDH2 mutant protein. Evaluation of immunolabeling was made for this last antibody by calculating a $\mathrm{H}$-score $(\%$ of positive stained cellsxintensity of the staining grade from 0 to 3 , results of $\mathrm{H}$-score must be ranged between 0 and 300).

All antibodies used and details regarding pretreatment, clones, dilutions, incubation times are summarized in Table 1.

\section{Molecular analysis}

\section{DNA and RNA extraction}

Formalin-fixed paraffin-embedded tumors were analyzed by one pathologist to determine the tumor cell content. Samples were macrodissected to obtain a tumor cell content of $80 \%$ at least. DNA was extracted using the Maxwell-16 formalin-fixed paraffin-embedded Plus LEV DNA purification kit (Promega) according to the manufacturer's protocol. DNA quality was assessed by spectrophotometry with absorbance at 230, 260 and $280 \mathrm{~nm}$. DNA was quantified using a fluorimetric assay with a Qubit device.

RNA was extracted using the Maxwell-16 LEV RNA formalin-fixed paraffin-embedded Purification kit (Promega) according to the manufacturer's protocol. RNA quality and quantity were assessed by spectrophotometry with absorbance at 230,260 and $280 \mathrm{~nm}$.

\section{Exome analysis}

A total of $200 \mathrm{ng}$ of genomic DNA was fragmented with a Coveris device to obtain fragments around $300 \mathrm{bp}$. Then, libraries were constructed and captured by using SureSelect Human All Exon v6 kit (Agilent), following the manufacturer's protocol. Paired-end $(2 \times 151$ bases $)$ sequencing was performed on a NextSeq500 device (Illumina). Obtained sequences were aligned and annotated with the human $\mathrm{Hg} 19$ genome based on the SureSelect Human all Exon v6 manifest by using BWA and GATK algorithms. Only sequences with a read depth of $10 \times$, a mutation allele frequency superior to $5 \%$ and a frequency in the general population inferior to $1 \%$ were conserved for the analysis.

\section{RNA sequencing}

RNA depleted of ribosomal RNA was used for the library preparation with a TruSeq RNA library Prep kit according to the manufacturer's instructions (Illumina). RNA sequencing was performed on a NextSeq500 device (Illumina). The libraries were sequenced with paired-end 76-base pair 'reads'. Analysis was performed with the splice junction mapper TopHat for Illumina on the human Hg19 genome. The files generated were processed with Cufflinks software to obtain annotated expressed genes in each studied subtype. 


\section{Statistical analysis}

Statistical analysis was performed using the open-source software R (https://cran.r-project.org/).

Calculations were performed using HPC (high performance computing) resources from PSIUN CCUB (Centre de Calcul de l'Université de Bourgogne).

\section{Exome analysis}

Gene mutations (whatever the nucleotide change) present in too many or too few patients were retrieved from the analysis (arbitrary thresholds were chosen). By this way, 1192 mutations were kept for further analysis. To select mutations specific to solid papillary carcinoma with reverse polarity and control samples, only mutations respectively (resp.) detected in more than $1 / 4$ of the solid papillary carcinoma with reverse polarity samples (resp. 1/4 of the control samples) and less than $10 \%$ (resp. 1/4) in the other diagnostic group were kept.

\section{RNA-sequencing}

RNA-Seq data were aligned to the transcriptome and reference genome with TopHat 2.1.1. The reference genome was downloaded on the UCSC (University of California, Santa Cruz) Genome Browser (hg19). Fragments per kilobase of transcript per million (FPKM) were calculated using Cufflinks 2.2.1. Differential genes were selected using the Cuffdiff program from Cufflinks through the cummeRbund $\mathrm{R}$ package [13, 14]. Only genes specific to the solid papillary carcinoma with reverse polarity patients with the false discovery rate-adjusted $p$-value under 0.05 were kept; by this way, 76 genes were selected [15]. Intrinsic molecular subtype classification from RNA-sequencing results was based on the PAM50 gene set [16]. It was performed by nearest centroid method and Spearman's correlation on the $\log 2$ transform of the FPKM RNA-seq values using the Bioconductor package genefu [15].

\section{Results}

\section{Clinicopathologic features}

A total of nine cases of solid papillary carcinoma with reverse polarity were retrieved. Six cases of each tumor controls were selected (six invasive micropapillary carcinoma, six encapsulated papillary carcinomas, six intraductal papillomas with usual hyperplasia and six solid papillary carcinomas).

The nine solid papillary carcinomas with reverse polarity occurred in women aged from 52 to 75 years $($ mean $=65.8$

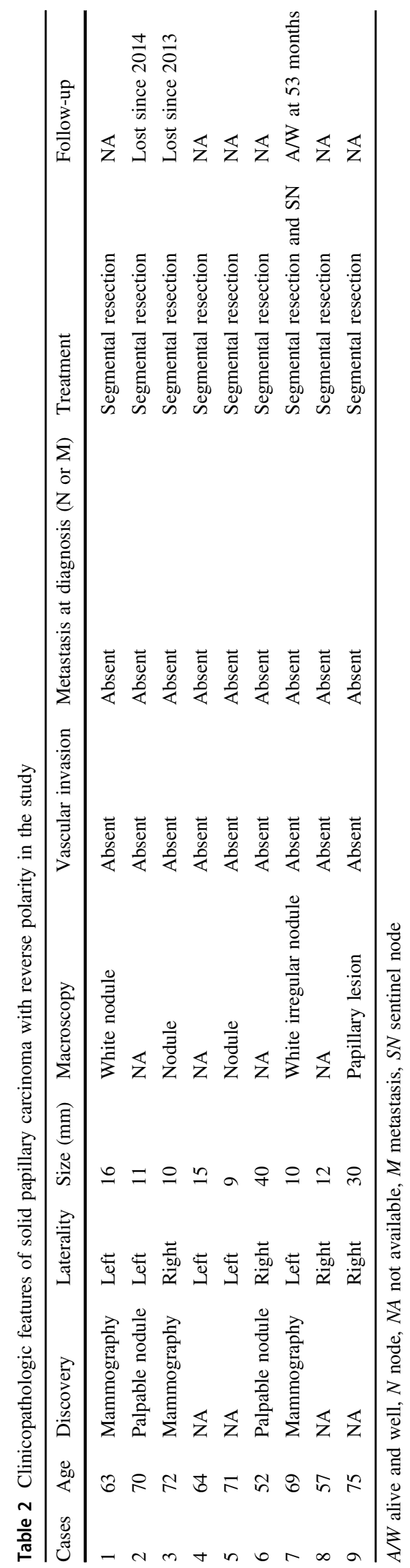




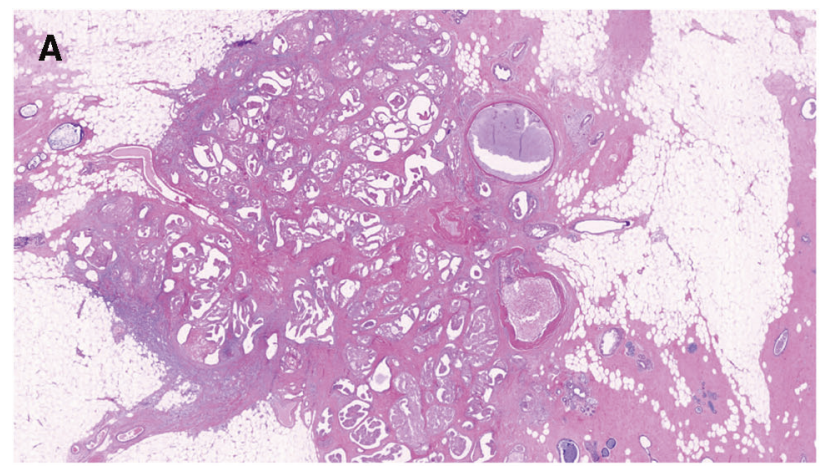

Fig. 1 a Low power view of solid papillary carcinoma with reverse polarity showing a unique well-delimited nodule of cystic architecture (hematoxylin-eosin-saffron). b Low power view of solid papillary

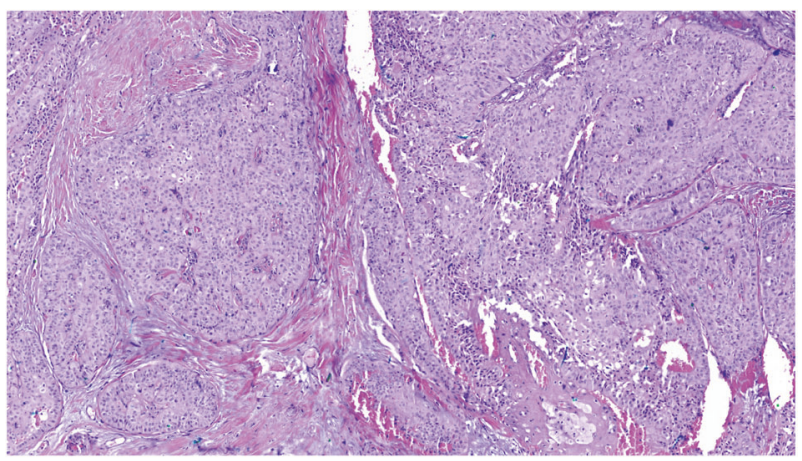

Fig. 2 Low power view of solid papillary carcinoma with reverse polarity showing a proliferation composed of nests with papillary structures closely packed. Nests are separated by dense fibrous stroma (hematoxylin-eosin-saffron)

years old). Three of them were discovered by mammography screening. For two patients, a single nodule was detected by palpation on physical examination. Information about the way of detection was not available for the other four patients. Five of them were localized in the left breast, four others in the right breast. Tumor size ranged from 9 to $40 \mathrm{~mm}($ mean $=17 \mathrm{~mm})$. Patient management always consisted in segmental resection, one patient had a sentinel lymph node procedure. For the three patients we had follow-up, there was no evidence of radiotherapy or chemotherapy. Clinicopathologic findings are listed in Table 2.

On macroscopic inspection, all solid papillary carcinomas with reverse polarity always consisted of a relatively well-circumscribed single nodule. Only one was described as slightly irregular.

On microscopical examination, all the tumors showed a well-delimited lesion. A solid papillary architecture (7/9) and a cystic architecture (2/9) were observed (Fig. 1a, b). The solid papillary architecture consisted in nests closely packed or separated by a dense fibrous stroma (Fig. 2). Papillae were always observed, lined by neoplastic cells and

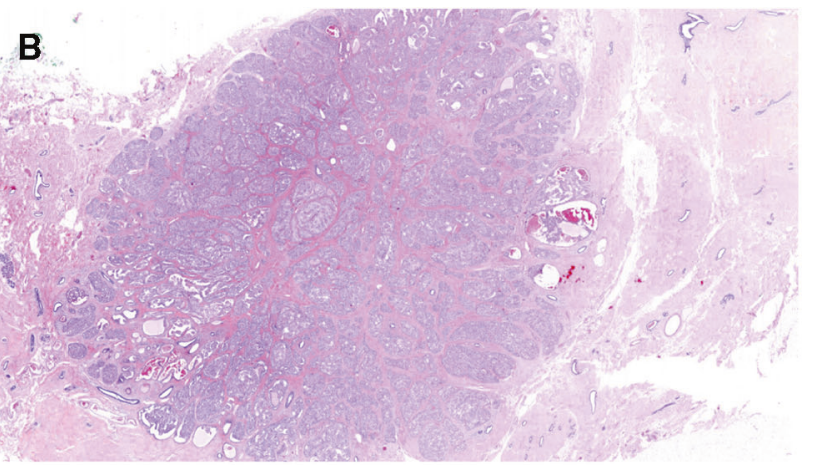

carcinoma with reverse polarity showing a solid architecture (hematoxylin-eosin-saffron)

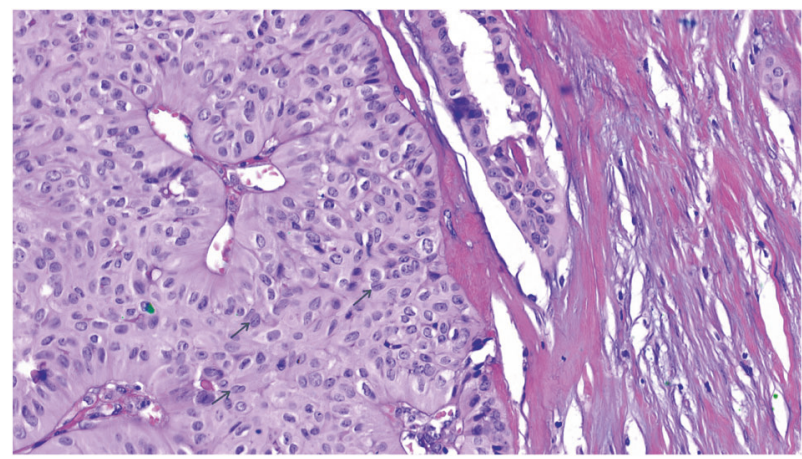

Fig. 3 High power view of solid papillary carcinoma with reverse polarity showing tumor cells with low-grade nuclear atypia. Tumor cells have abundant eosinophilic cytoplasms and ovoid nuclei. Some nuclei show nuclear grooves (arrows) (hematoxylin-eosin-saffron)

centered by fibrovascular cores, sometimes containing foamy macrophages (3/9). In some areas of the tumor, a gyrate architecture was identified with concentric arrangement of the rows of epithelial cells.

In each tumor, neoplastic cells were columnar to cuboidal, and were positioned back to back. Cytoplasms were abundant, eosinophilic or clear. Mild nuclear atypia was observed. Nuclei were slightly increased in size, ovoid, sometimes grooved (Fig. 3), with rare nuclear pseudoinclusions. One of the cases (case 9) showed small nucleoli. For all cases, chromatin was clear and no or rare mitotic figures or prominent nucleoli were observed. In each tumor, nuclei were localized at the apical side of the cytoplasm, far away from the basal layer, giving the impression of reverse polarity (Fig. 4a, b). In all these cases myoepithelial cells surrounding the nodule or surrounding fibrovascular cores were always absent. Eosinophilic and dense secretions were noted in three of nine cases (Fig. 5). No psammoma bodies or necrotic areas were observed.

For invasive micropapillary carcinoma, encapsulated papillary carcinoma, intraductal papilloma with usual ductal 


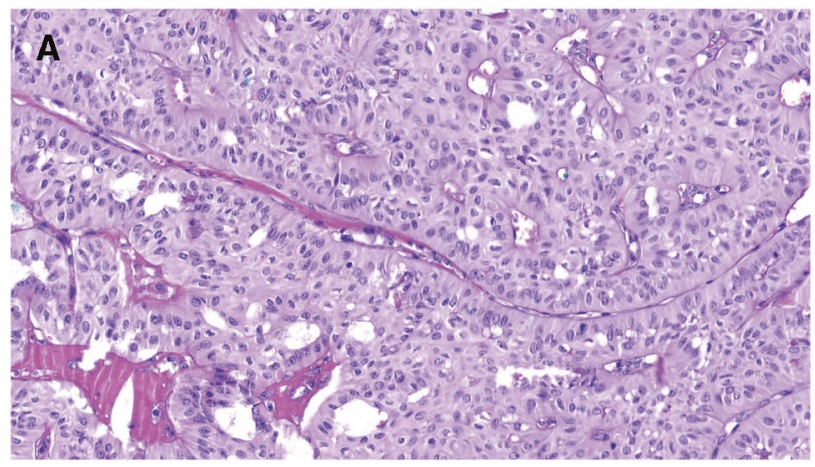

Fig. 4 a Higher power view showing that solid papillary carcinoma with reverse polarity consists of numerous papillae closely packekd with cuboid to colomnar neoplastic cells. b Higher magnification focusing on one papillary structure. Tumor cells own cytoplasm which

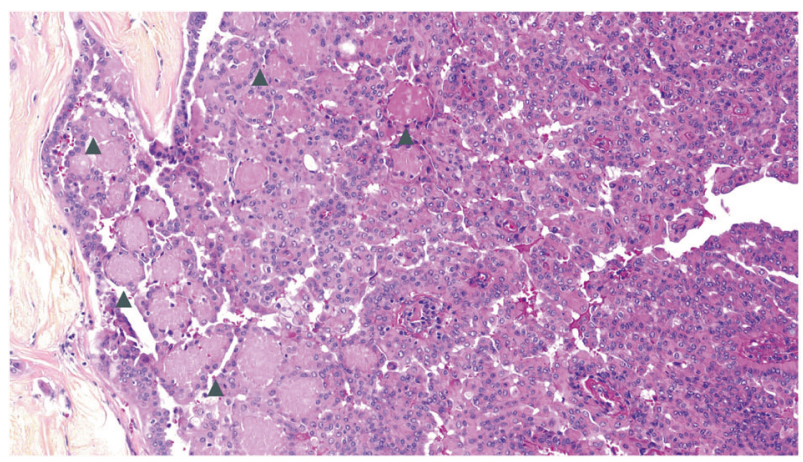

Fig. 5 Eosinophilic and dense secretions can be observed in solid papillary carcinoma with reverse polarity (arrows) (hematoxylin-eosin-saffron)

hyperplasia and solid papillary carcinoma, mean age for each tumor group was respectively $67.5,69,60$ and 75.5 years.

The six cases of encapsulated papillary carcinoma and intraductal papilloma also consisted of a well-delimited intraductal or intracystic epithelial tumor, containing separated papillae or nests of cuboidal to columnar epithelial cells. The six cases of encapsulated papillary carcinoma showed nuclei of low to mild grade. All intraductal papilloma with usual ductal hyperplasia showed myoepithelial cells, interposed between the fibrovascular cores and the epithelial cell layer.

The six cases of solid papillary carcinoma consisted of multiples solid nodules, with rare thin fibrovascular cores that were difficult to highlight. In these tumors, epithelial cells may sometimes harbor neuroendocrine features with eosinophilic granulations in cytoplasms. Areas of spindle cells were observed in one case. Rare pool of extracellular mucin was also described in few cases of SPC.

For invasive micropapillary carcinoma, tumors showed more irregular margins. Tumor cells were arranged in

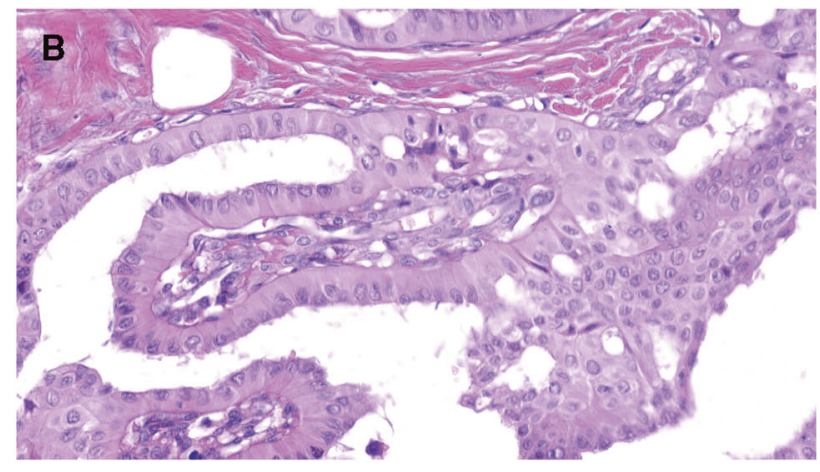

is located near the basal layer and near the fibrovascular cores, whereas the nucleus is located at the opposite side, giving the impression of reverse polarity (hematoxylin-eosin-saffron)

micropapillae separated from the stroma by an empty clear space and forming clusters of carcinomatous cells, without stromal cores. Nuclear polarity abnormalities sometimes mimicking inverted polarity were described in the six cases.

\section{Immunohistochemical features}

Tumor cells of solid papillary carcinoma with reverse polarity showed a diffuse and strong cytoplasmic expression with CK7 (9/9 cases diffuse). Eight of nine cases showed positive staining with CK5/6 except for one case (case 9). Myoepithelial markers, p63 and calponin, were negative in $100 \%$ of solid papillary carcinoma with reverse polarity $(0 / 9), 100 \%$ of encapsulated papillary carcinoma (0/6), of invasive micropapillary carcinoma (0/6) and of solid papillary carcinoma (0/ 6). Contrariwise, immunostaining with both markers was observed in intraductal papillomas with usual ductal hyperplasia (6/6), along the fibrovascular cores or in the capsule surrounding the lesion. Breast origin supported by GCDFP-15 staining was seen in $78 \%$ of solid papillary carcinomas with reverse polarity (7/9 cases focal) and in $78 \%$ of other group tumors (14/24). Rare scattered reactivity for hormonal receptors (ER, PR) not exceeding more than $5 \%$ of nuclei was identified in seven of nine cases of solid papillary carcinomas with reverse polarity (78\%). Expression of HER2 was negative for all solid papillary carcinomas with reverse polarity. Expression of AR was absent or low $(\leq 10 \%)$ in $78 \%$ of these tumors. The 24 other papillary breast tumors studied showed a higher hormonal receptor expression (ER, PR and AR) ranging from 50 to $100 \%$ of positive tumor cells. Expression of HER2 in these other papillary breast tumors was negative $(19 / 24)$ or weak $(1+)(5 / 24)$. TTF1 was negative for all breast tumors studied. Seven solid papillary carcinomas with reverse polarity $(78 \%)$ had a low Ki67 proliferation index valued at 1 or $2 \%$. Two solid papillary carcinomas with reverse polarity showed higher Ki67 rate, case 4 and case 9 with 6 and 15\% tumor cell positivity, respectively. Invasive micropapillary 

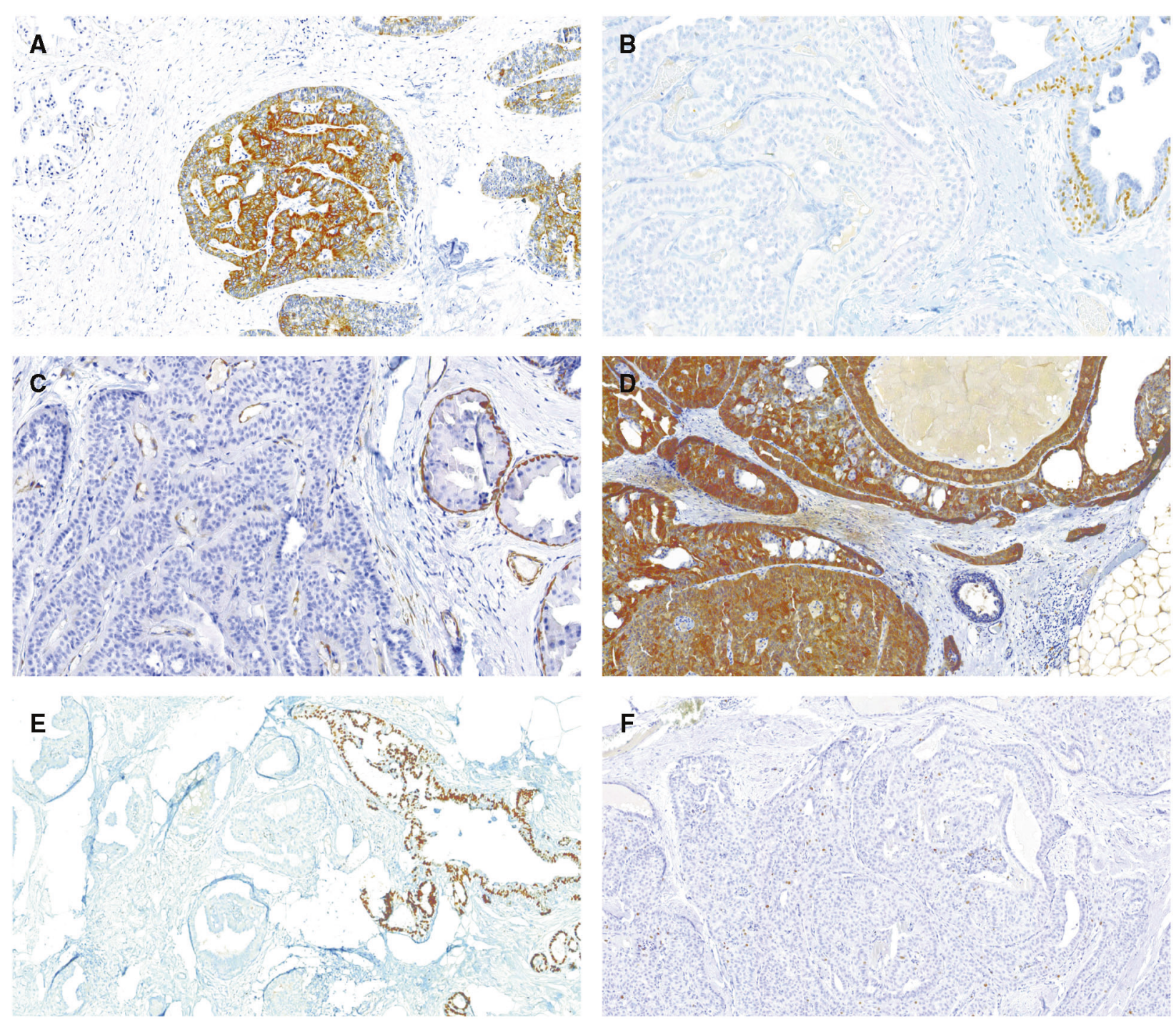

Fig. 6 Immunohistochemical findings of solid papillary carcinoma with reverse polarity. a Diffuse and strong cytoplasmic immunostaining in tumor cells for CK5/6. b Negativity for myoepithelial markers as p63. c Negativity for myoepithelial markers as calponin. d

Diffuse and strong immunostaining for calretinin. e Low and weak nuclear immunostaining for estrogen receptor in tumor cells. f Low Ki67 proliferation index in tumor cells

carcinoma showed the highest Ki67 proliferation rate, then solid papillary carcinoma, encapsulated papillary carcinoma and intraductal papilloma with usual ductal hyperplasia, with respectively mean Ki67 values estimated at $28 \%, 9 \%, 7 \%$ and $2 \%$. All solid papillary carcinomas with reverse polarity showed calretinin expression (9/9: six cases strong and diffuse and three cases focal). Ninety two percent (22/24) of remaining cases were negative for calretinin. Two of six intraductal papillomas with usual ductal hyperplasia (33\%) showed focal and weak calretinin staining. Chromogranin A and synaptophysin were negative in all the groups except in solid papillary carcinomas. In this group, weak and focal positive immunostaining with neuroendocrine markers was observed in $67 \%$ of cases.
Main solid papillary carcinomas with reverse polarity immunohistochemical features are illustrated in Fig. 6a-f and all immunohistochemical results are detailed in Table 3.

\section{IDH2 expression}

We observed a strong and diffuse positive staining of tumor cells in six solid papillary carcinomas with reverse polarity (6/9) with the IDH1/2 mutant antibody (Fig. 7) with a Hscore ranging from 120 to 300 (mean H-score: 191). One tumor (case 8) showed a weak immunolabeling with this antibody (H-score: 50). All breast tumors in other groups were negative with this IDH1/2 mutant antibody, except 


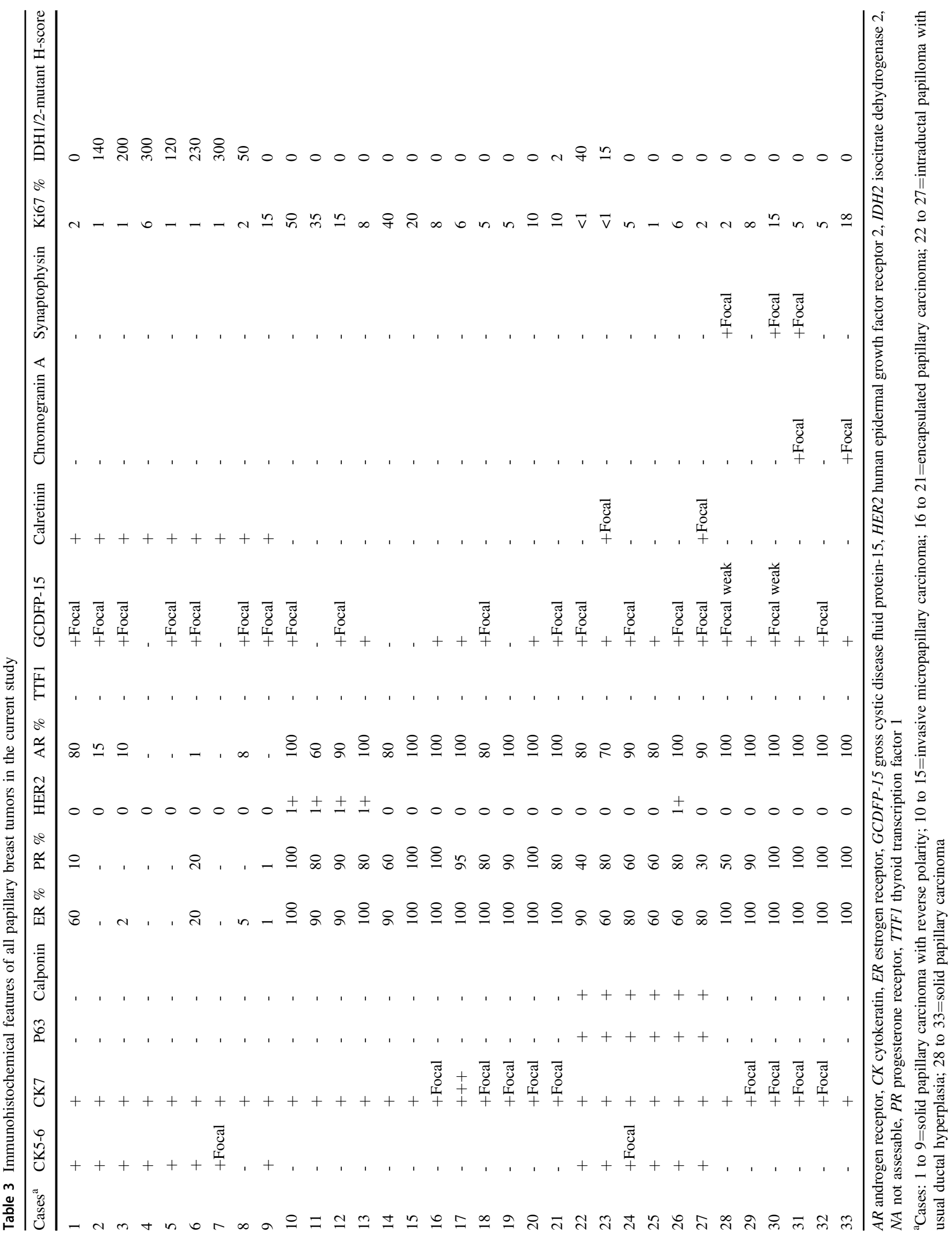


two cases of intraductal papilloma with usual ductal hyperplasia that were weakly and focally stained (low H-score $\leq 40)$. Normal breast epithelial cells surrounding proliferation were not stained by this antibody.

Main differences including both pathologic and immunohistochemical features between these five groups are summarized in Table 4.

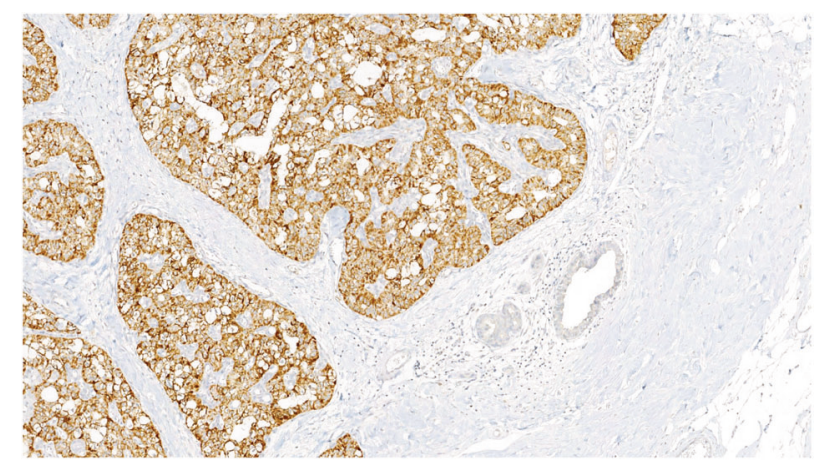

Fig. 7 Tumor cells of solid papillary carcinoma with reverse polarity showing a strong cytoplasmic immunostaining for MsMab-1 (IDH2 mutant antibody). Normal breast tissue is observed at the right side of the picture and is negative for this marker

\section{Molecular analysis}

\section{Genetic and transcriptomic profiles of solid papillary carcinomas with reverse polarity}

Exome analysis of the 9 solid papillary carcinomas with reverse polarity (cases 1 to 9) and the 24 control samples (invasive micopapillary carcinomas: cases 10 to 15 ; encapsulated papillary carcinomas: cases 16 to 21 ; intraductal papillomas with usual ductal hyperplasia: cases 22 to 27; and solid papillary carcinomas: cases 28 to 33 ) revealed that $I D H 2$ harbored a hotspot mutation located on the arginine 172 (changed in glycine, serine or threonine) that was observed in 78\% (7/9) of solid papillary carcinomas with reverse polarity and not in any controls. All gene variations are summarized in Table 5.

Other genes were more often altered in solid papillary carcinomas with reverse polarity than in the control groups. Among these genes, we also found PRUNE2 that showed variations in 67\% (6/9) in this group and in 17\% (4/24) of the controls, with a recurrent splicing mutation observed in three solid papillary carcinomas with reverse polarity. The $A C A C B$ gene harbored variations in 56\% (5/9) and in $8 \%$ $(2 / 24)$ of controls. All solid papillary carcinomas with reverse polarity showed an alteration in, at least, one of

Table 4 Main histological and immunohistochemical findings of all papillary breast tumors in the current study

\begin{tabular}{|c|c|c|c|c|c|}
\hline & SPCRP $(n / 9)$ & $\operatorname{IMPC}(n / 6)$ & $\operatorname{EPC}(n / 6)$ & IDPUDH $(n / 6)$ & $\operatorname{SPC}(n / 6)$ \\
\hline Architecture & $\begin{array}{l}\text { Papillary, solid and } \\
\text { cystic }(9 / 9)\end{array}$ & Micropapillary (6/6) & Papillary $(6 / 6)$ & Papillary $(6 / 6)$ & $\begin{array}{l}\text { Papillary and solid } \\
(6 / 6)\end{array}$ \\
\hline Epithelial cell pattern & $\begin{array}{l}\text { One population cell } \\
\text { organized }\end{array}$ & $\begin{array}{l}\text { One population cell } \\
\text { organized }\end{array}$ & $\begin{array}{l}\text { One population cell } \\
\text { organized }\end{array}$ & $\begin{array}{l}\text { Two population } \\
\text { cell jumbled }\end{array}$ & $\begin{array}{l}\text { One population cell } \\
\text { organized }\end{array}$ \\
\hline Nuclear reverse polarity & Present (9/9) & Absent (0/6) & Absent (0/6) & Absent $(0 / 6)$ & Absent $(0 / 6)$ \\
\hline $\begin{array}{l}\text { Myoepithelial cells markers (p63 } \\
\text { and calponin) }\end{array}$ & Absent (9/9) & Absent $(0 / 6)$ & Absent (0/6) & Present $(0 / 6)$ & Absent $(0 / 6)$ \\
\hline CK5/6 & Positive (8/9) & Negative (0/6) & Negative $(0 / 6)$ & Positive $(0 / 6)$ & Negative $(0 / 6)$ \\
\hline CK7 & Positive (9/9) & Positive (6/6) & $\begin{array}{l}\text { Positive or focal (6/ } \\
6)\end{array}$ & Positive (6/6) & $\begin{array}{l}\text { Positive or focal (6/ } \\
6)\end{array}$ \\
\hline Calretinin & Positive (9/9) & Negative $(0 / 6)$ & Negative $(0 / 6)$ & $\begin{array}{l}\text { Focal positivity }(2 / \\
6)\end{array}$ & Negative $(0 / 6)$ \\
\hline ER \% & $\begin{array}{l}\text { Low }(<10 \%) \\
(7 / 9)\end{array}$ & $\begin{array}{l}\text { High }(\geq 80 \%) \\
(6 / 6)\end{array}$ & $\begin{array}{l}\text { High }(\geq 80 \%) \\
(6 / 6)\end{array}$ & $\begin{array}{l}\text { High }(\geq 80 \%) \\
(5 / 6)\end{array}$ & $\begin{array}{l}\text { High }(\geq 80 \%) \\
(6 / 6)\end{array}$ \\
\hline Ki67 \% & $\begin{array}{l}\leq 5 \% \\
(7 / 9)\end{array}$ & $\begin{array}{l}\geq 20 \% \\
(4 / 6)\end{array}$ & $\begin{array}{r}\geq 5 \% \\
(6 / 6)\end{array}$ & $\begin{array}{l}\leq 5 \% \\
(5 / 6)\end{array}$ & $\begin{array}{l}\geq 5 \% \\
(5 / 6)\end{array}$ \\
\hline $\begin{array}{l}\text { Neuroendocrine markers } \\
\text { (chromogranin and } \\
\text { synaptophysin) }\end{array}$ & $\begin{array}{l}\text { Negative } \\
(0 / 9)\end{array}$ & $\begin{array}{l}\text { Negative } \\
(0 / 6)\end{array}$ & $\begin{array}{l}\text { Negative } \\
(0 / 6)\end{array}$ & $\begin{array}{l}\text { Negative } \\
(0 / 6)\end{array}$ & $\begin{array}{l}\text { Positive } \\
(4 / 6)\end{array}$ \\
\hline $\begin{array}{l}\text { IDH1/2 mutant } \\
\text { MsMab-1 }\end{array}$ & $\begin{array}{l}\text { Strongly positive } \\
(7 / 9)\end{array}$ & $\begin{array}{l}\text { Negative } \\
(0 / 6)\end{array}$ & $\begin{array}{l}\text { Negative } \\
(0 / 6)\end{array}$ & $\begin{array}{l}\text { Negative or weak } \\
(2 / 6)\end{array}$ & $\begin{array}{l}\text { Negative } \\
(0 / 6)\end{array}$ \\
\hline
\end{tabular}

$C K 5 / 6$ and $C K 7$ cytokeratins 5/6 and 7, EPC encapsulated papillary carcinoma, ER estrogen receptor, $I D H 2$ isocitrate dehydrogenase 2, IDPUDH intraductal papilloma with usual ductal hyperplasia, IMPC invasive micropapillary carcinoma, SPC solid papillary carcinoma, SPCRP solid papillary carcinoma with reverse polarity 
Table 5 Gene variations for all cases of papillary and micropapillary breast lesions in the current study

\begin{tabular}{|c|c|c|c|c|}
\hline Gene & Variation & $\begin{array}{l}\text { Putative } \\
\text { impact }^{\#}\end{array}$ & SPCRP & Controls \\
\hline \multirow[t]{6}{*}{$A C A C B$} & p.R189Q & Neutral & 3 & \\
\hline & p.D793N & Neutral & 2 & \\
\hline & p.H1240N & Deleterious & & 18 \\
\hline & p.D1481V & Deleterious & 7 & 33 \\
\hline & p.D2409N & Deleterious & 1 & \\
\hline & c. $1117+4 \mathrm{G}>\mathrm{A}$ & Splicing & 4 & \\
\hline \multirow[t]{3}{*}{$I D H 2$} & p.R172G & Deleterious & $5,6,7$ & \\
\hline & p.R172S & Deleterious & $2,3,4$ & \\
\hline & p.R172T & Deleterious & 8 & \\
\hline \multirow[t]{12}{*}{ PRUNE2 } & p.D99N & Neutral & & 24 \\
\hline & p.W1316* & Deleterious & 3 & \\
\hline & p.P1495L & Neutral & 2 & \\
\hline & p.E1877K & Neutral & 3 & \\
\hline & p.G1900R & Neutral & 8 & \\
\hline & p.E1957_Q1961del & Unknown & 1 & \\
\hline & c. $509-2 \mathrm{~A}>\mathrm{G}$ & Splicing & 9 & \\
\hline & c. $757-7 \mathrm{G}>\mathrm{A}$ & Unknown & & 20 \\
\hline & c. $9051-1 \mathrm{G}>\mathrm{T}$ & Splicing & 4 & \\
\hline & c.9051-3delT & Splicing & $1,3,4$ & 28 \\
\hline & p.N1608S & Neutral & & 31 \\
\hline & p.M179T & Neutral & & 31 \\
\hline FOXF2 & p.G301dup & Neutral & 2,6 & $\begin{array}{l}11,12,14, \\
17-19,21, \\
24-33\end{array}$ \\
\hline
\end{tabular}

SPCRP solid papillary carcinoma with reverse polarity

Cases 1 to $9=$ solid papillary carcinoma with reverse polarity; 10 to $15=$ invasive micropapillary carcinoma; 16 to $21=$ encapsulated papillary carcinoma; 22 to $27=$ intraductal papilloma with usual ductal hyperplasia; 28 to $33=$ solid papillary carcinoma

"Prediction of pathogenicity obtained with the PROVEAN website

these genes. We also analyzed variations in TET2 and $P I K 3 C A$ genes. In all samples, we identified five mutations in TET2 with only one in an IDH2 wild-type solid papillary carcinoma with reverse polarity. Concerning PIK3CA, 67\% (6/9) of these tumors had an activating mutation and $41 \%$ (10/24) of controls. Concomitant mutation in PIK3CA and $I D H 2$ genes were identified in $56 \%$ of solid papillary carcinomas with reverse polarity (5/9 cases).

Transcriptomic analysis revealed that solid papillary carcinomas with reverse polarity presented a specific RNA expression profile of 76 overexpressed genes compared to controls (Fig. 8). The pathway enrichment analysis, performed with these 76 genes by the Enrichr website, highlighted that, in the KEGG (Kyoto Encyclopedia of Genes and Genomes) database, only one pathway was significantly (adjusted $p=0.0011$ ) enriched in solid papillary carcinomas with reverse polarity group: proteoglycans. Intrinsic subtype classification made from RNA-sequencing showed that five of the nine tumors were considered as luminal A and four other as basal. This classification associated to the immunophenotype profile (CK5/6, ER and $\mathrm{Ki} 67$ ) is summarized in Table 6.

\section{Discussion}

Solid papillary carcinomas with reverse polarity represent a specific group of rare breast neoplasms consisting of papillary architecture, which may resemble morphologically to other benign or malignant breast lesions. In this study, we characterize, in comparison with intraductal papillomas with usual ductal hyperplasia, encapsulated papillary carcinomas, solid papillary carcinomas and invasive micropapillary carcinomas, and the morphologic, immunohistochemical and genomic profiles of this rare papillary tumor. From these three perspectives, we show that this papillary breast tumor was different from the other papillary breast lesions studied. In terms of genetic alterations, thanks to whole-exome analysis by next-generation sequencing, we confirm one noticeable genetic alteration in this group, totally absent in others tumor controls, which is an $I D H 2$ hotspot mutation at R172 (7/9 cases). We identified other gene variations like PRUNE2 and $A C A C B$ that were also significantly present in this category compared to the other tumor controls. From the transcriptomic analysis, a specific RNA expression profile of 76 overexpressed genes was identified compared to controls.

On microscopic examination, solid papillary carcinoma with reverse polarity has effectively a papillary, solid or cystic architecture, as can be observed in papilloma and in encapsulated papillary carcinoma. In this tumor, papillary cores are lined by cuboidal to columnar epithelial cells. Nuclei often own grooves, clearing aspects and some pseudoinclusions. Sometimes, scattered eosinophilic secretions are seen within the proliferation. Historically, this is precisely those histological and cytological features that resemble the tall cell variant of papillary thyroid carcinoma, suggesting a possibility of metastasis from the thyroid. Eusebi et al. [3] first drew attention on these histologic features close to papillary thyroid carcinoma. This resemblance has been addressed with in previous studies [5, 6]. Thyroid markers such as TTF1 and thyroglobulin, enabling to characterize nearly $100 \%$ of papillary thyroid carcinomas [17], were tested on all solid papillary carcinomas with reverse polarity and were always negative in previous studies [3, 5-12]. In the present study, mutations associated to papillary thyroid carcinoma as BRAF or RET were not identified in our series of solid papillary carcinoma with reverse polarity, as in the Hameed et al. [4] study, with a special focus on $B R A F^{\mathrm{V} 600 \mathrm{E}}$ that had been recently 

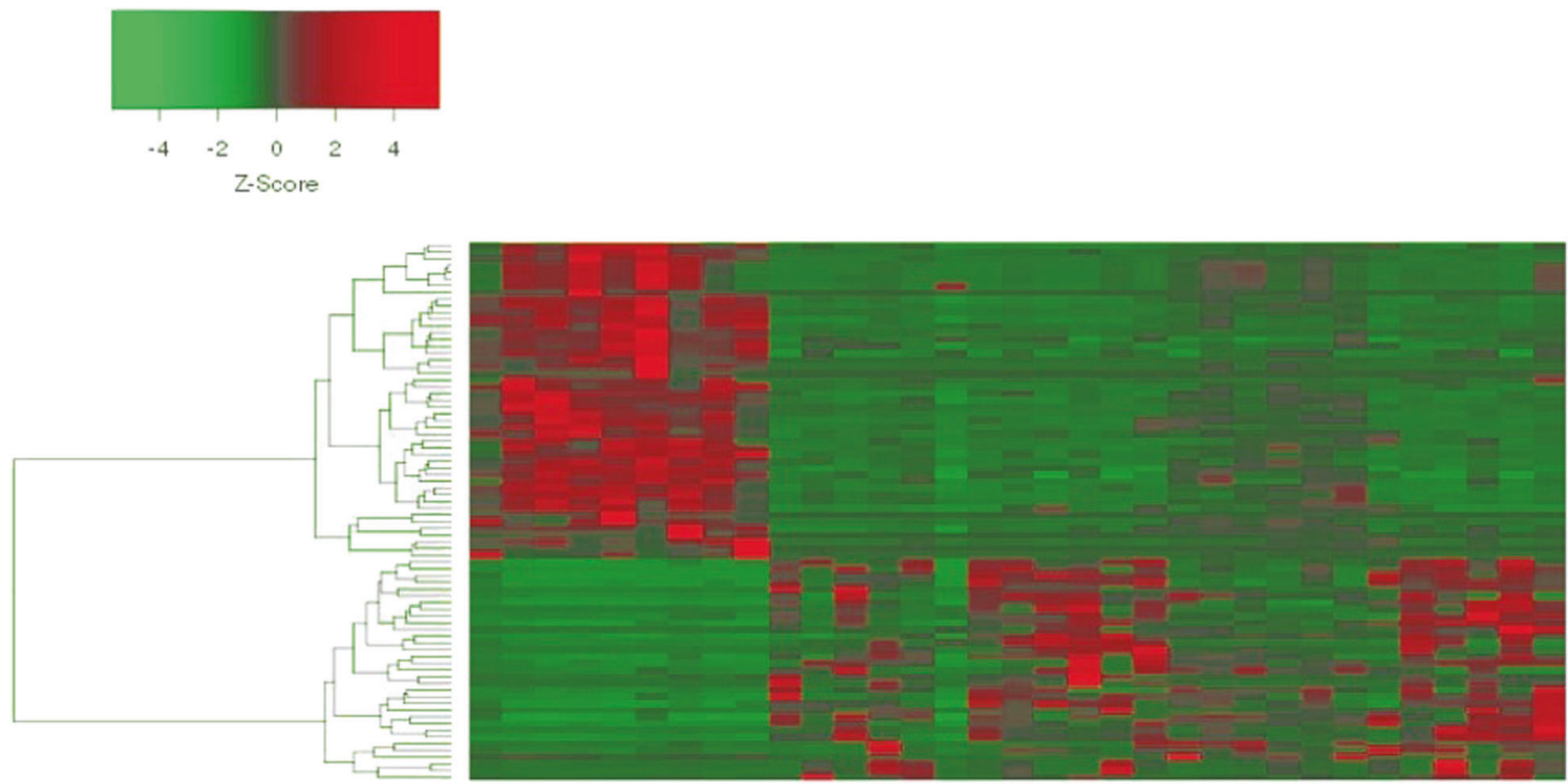

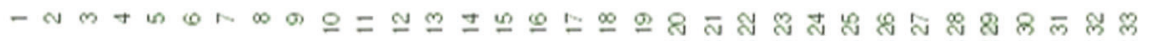

Fig. 8 Heatmap representing selected genes by RNA-sequencing in rows and patients in columns. Column names correspond to the sample identification numbers. Green cells correspond to under-expressed genes and red to overexpressed genes. Solid papillary carcinoma with reverse polarity cases (from 1 to 9) show the same group of

Table 6 Immunohistochemical findings of solid papillary carcinoma with reverse polarity and intrinsic molecular subtype classification from RNA-sequencing

\begin{tabular}{llllll}
\hline Cases & ER $\%$ & PR $\%$ & Ki67 \% & CK5-6 & $\begin{array}{l}\text { Intrinsic molecular } \\
\text { subtype classification by } \\
\text { RNA-seq }\end{array}$ \\
\hline 1 & 60 & 10 & 2 & + & Luminal A \\
2 & 0 & 0 & 1 & + & Luminal A \\
3 & 2 & 0 & 1 & + & Basal \\
4 & 0 & 0 & 6 & + & Basal \\
5 & 0 & 0 & 1 & + & Basal \\
6 & 20 & 20 & 1 & + & Luminal A \\
7 & 0 & 0 & 1 & + Focal & Luminal A \\
8 & 5 & 0 & 2 & - & Luminal A \\
9 & 1 & 1 & 15 & + & Basal \\
\hline
\end{tabular}

$C K$ cytokeratin, $E R$ estrogen receptor, $P R$ progesterone receptor, $R N A$ seq RNA sequencing

described as frequently associated to the tall variant of papillary thyroid carcinoma [18]. Extensive molecular analysis of this thyroid carcinoma did not reveal altered genes in common with solid papillary carcinoma with reverse polarity of the breast except PIK3CA [19]. Despite this resemblance, the hypothesis of any link between thyroid carcinoma and this papillary breast tumor has definitely been abandoned. overexpressed genes. Patients from 10 to 33, except patient 15, with other papillary tumors, show different overexpressed genes. Those of solid papillary carcinoma with reverse polarity overexpressed are under-expressed

One of the striking morphologic features that can be helpful to recognize this peculiar papillary breast tumor is the nuclear reverse polarity of the epithelial cells. This finding is recurrent in the cases studied and is not present in the comparative groups. To note, on microscopy, invasive micropapillary carcinomas display abnormalities of polarity but not strict reverse nuclear polarity that is defined by the presence of nuclei near the apical layer. In a series of 13 solid papillary carcinomas with reverse polarity, Chiang et al. [10] also noticed that nuclei were present at the apical side rather to basal pole of the cells. In the present study, transcriptomic analyses revealed a proteoglycan pathway enrichment (KEGG database). Proteoglycans are implicated in cellular growth and differentiation control [20]. Glypican belongs to proteoglycans family and has been described in breast cancer with different conclusions [21, 22] but the understanding of functions is still limited. The control of cell polarity in zebrafish by one of the glypican family members has been established in a functional study [23]. The significant enrichment of this pathway in solid papillary carcinoma with reverse polarity could partially explain the polarity alteration of these tumors but needs to be explored in more detail.

From an immunohistochemical perspective, solid papillary carcinomas with reverse polarity are defined by the lack of any myoepithelial cell and, therefore, by the absence of immunostaining with myoepithelial markers (p63 and calponin). This point is crucial to diagnose this tumor and may 
support the hypothesis, although controversial that solid papillary carcinoma with reverse polarity is not strictly speaking an in situ carcinoma, at least like encapsulated papillary carcinoma and solid papillary carcinoma [24]. They also present a low Ki67 proliferation index and a low hormonal receptor rate. Another interesting point in this study was the unexpected immunostaining with calretinin. In this study, most of solid papillary carcinomas with reverse polarity were stained by this antibody (7/9 cases). We also observed that two papillomas were focally positive with calretinin. Calretinin is a calcium-binding protein, widely used to identify mesothelial origin, especially mesothelioma or some ovarian sex cord tumors. Calretinin expression has already been reported in normal breast tissues and breast carcinoma [25]. In three studies, this marker was associated to breast carcinoma of worse prognosis, especially of basal-like phenotype [26-28].

To the best of our knowledge, this is the first study that compares solid papillary carcinoma with reverse polarity and other breast papillary and micropapillary lesions on three overriding and complementary perspectives. The rarity of cases reported in literature, the absence of this entity in the 2012 WHO (World Health Organization) classification of breast tumors [29] suggests that this papillary breast tumor was actually not well known. The point is that it effectively shares common characteristics with other papillary lesions, besides the papillary pattern. To begin, solid papillary carcinomas with reverse polarity share grooved nuclei and pseudo inclusions with intraductal papillomas with usual ductal hyperplasia. These cytological aspects had already been described arising in papilloma with usual ductal hyperplasia [30]. Both also express CK5/6 and have a low Ki67 proliferation index. The main difference between these lesions is the presence of myoepithelial cells in papilloma. Encapsulated or solid papillary carcinoma and invasive micropapillary carcinoma have in common with solid papillary carcinoma with reverse polarity the lack of myoepithelial cells, emphasized by the absence of calponin and p63 immunostaining. The main difference between these three lesions and solid papillary carcinoma with reverse polarity is the CK5/6 negativity and the strong hormonal receptor positivity in these three groups.

Thanks to the whole comparative analysis of these five close groups of breast tumor, we highlighted in terms of molecular data some specific features supporting the singularity of solid papillary carcinoma with reverse polarity.

Indeed, one of the most interesting findings highlighted by the molecular analysis is certainly that they harbored a recurrent IDH2 hotspot mutation at R172 (7/9 cases), whereas no other papillary breast lesion studied in this series harbored it. Thereby, this particular IDH2 mutation appears as a distinctive criterion and could characterize it. This result perfectly agrees with those of Chiang et al. [10].
They recently described $I D H 2$ mutations in 10 of 13 tumors and defined it with concomitant PIK3 alteration as a molecular signature through their functional study. Recently, Bhargava et al. [9] also highlighted this mutation in two of three tumors. IDH2 mutation is not frequent in breast pathology and has been described in several malignant tumors such as gliomas [31], myeloid malignancies [32], and also intrahepatic cholangiocarcinomas [33], cartilaginous and bone tumors [34-36]. Usually, IDH gene encodes for one enzyme that catalyzes the conversion of Isocitrate into alpha ketoglutarate (alphaKG) [37]. When the mutation occurs at arginine 172 in gene encoding for $I D H 2$, a function gain is seen. The enzyme is then able to produce an oncometabolite 2-hydroxyglutarate (2-HG). Comprehensive studies demonstrated that the production of this oncometabolite leads to a block in cellular differentiation in tumor [38] or increase of stem cells in leukemia [39].

Faced with this particular mutation found in our series, and previously described in two recent studies $[9,10]$, we sought to find a simpler way to identify IDH 2 mutations by IHC. Indeed, we are the first to describe in breast, positivity for an IDH1/2 mutant antibody (MsMab-1), in correlation with the genomic mutation. Indeed, we tested this multispecific antibody of the IDH $1 / 2$ mutant protein (at arginine 172) on all cases of the study. Six of the seven solid papillary carcinomas with reverse polarity harboring an IDH 2 mutation were stained by MsMab- 1 with a $\mathrm{H}$-score of $>100$. These results demonstrated a strong correlation between immunochemistry and exome data and can be useful to determine IDH2 mutations before DNA sequencing. To note, the MsMab-1 efficiency has been reported in two others studies, demonstrating positivity in giant cell tumor of bone [34, 40] and in osteosarcoma [36].

We identified PRUNE2 gene mutations in $67 \%$ of solid papillary carcinoma with reverse polarity including the two tumors $I D H 2$ wild type. PRUNE2 gene has been explored in prostate cancer [41] and parathyroid carcinoma [42], and could suppress the cellular transformation [43].

The phosphatidylinositol-3-kinase (PIK3) cell signaling pathway is often dysregulated and activated in human cancers, and in more than half of breast invasive tumors [44]. We identified PIK3CA or PIK3RI alterations in all our study groups, regardless of malignancy. Indeed, this alteration does not appear specific, and we identified it in $67 \%$ of solid papillary carcinomas with reverse polarity. Concerning PIK3CA, 67\% of solid papillary carcinomas with reverse polarity had an activating mutation and $41 \%$ other papillary breast tumors. Troxell et al. [45] identified PIK3CA alteration in papillary neoplasms of the breast with a high prevalence, especially for papilloma with usual ductal hyperplasia. In our series, we also identified a TET2 mutation occurring in one $I D H 2$ wild-type solid papillary carcinoma with reverse polarity similar to the one described 
in the Chiang et al. [10] study. However, TET2 mutation was also present in four other papillary breast lesions in our series.

In this particular tumor and in this small number of cases, we did not find any concordance between intrinsic molecular classification and immunophenotypic profile (CK5/6, ER, Ki67). In other breast tumors, correlation between immunochemistry profile and molecular classification is not always absolute. In Nielsen et al. [46] series, $10 \%$ of breast tumors were assigned to nonluminal subtypes despite their ER positivity. In the same way, Rakha et al. [47] demonstrated that some cases of triple-negative tumors are not always basal-like tumors.

Concerning the prognosis of solid papillary carcinoma with reverse polarity, despite the low number of available follow-up of patients in the present series for this group and in literature, only four patients presented lymph node metastasis $[5,6,12]$ with one associated to bone metastasis [6]. The low prevalence of reported metastasis in literature, subject to not only the current number of reported cases, but also the low Ki67 proliferation index, the well-delimited morphology and the absence of necrosis or mitoses, strongly suggest these tumors are of favorable prognosis. Further studies are warranted to better assess their prognosis. However, in the event of an unlikely metastatic evolution, the presence of an $I D H 2$ mutation could enable the use of IDH2 inhibitors currently under development for hematologic malignancies [48].

In summary, despite the small number of solid papillary carcinoma with reverse polarity in this series, it represents the third largest described in the literature. We highlight microscopic-, immunohistochemical- and molecularspecific features that distinguish this breast tumor from other breast papillary and micropapillary lesions. Reverse nuclear polarity, nuclear grooves, lack of myoepithelial cells, low or negative hormonal receptor expression, positivity for $\mathrm{CK} 5 / 6$, calretinin and IDH2 mutant antibody together represent the hallmark of this tumor. In addition, solid papillary carcinoma with reverse polarity harbors frequent specific mutations as IDH2 (R172) and/or PRUNE2 that can help in the diagnosis of this rare and intriguing entity.

\section{Compliance with ethical standards}

Conflict of interest The authors declare that they have no conflict of interest.

\section{References}

1. Guinebretière J-M. Proliférations papillaires du sein. Bulletin de la Division Française de l'Académie Internationale de Pathologie. Bulletin 2013;57:39.
2. Agoumi M, Giambattista J, Hayes MM. Practical considerations in breast papillary lesions: a review of the literature. Arch Pathol Lab Med. 2016;140:770-90.

3. Eusebi V, Damiani S, Ellis IO, et al. Breast tumor resembling the tall cell variant of papillary thyroid carcinoma: report of 5 cases. Am J Surg Pathol. 2003;27:1114-8.

4. Hameed O, Perry A, Banerjee R, et al. Papillary carcinoma of the breast lacks evidence of RET rearrangements despite morphological similarities to papillary thyroid carcinoma. Mod Pathol. 2009;22:1236-42.

5. Tosi AL, Ragazzi M, Asioli S, et al. Breast tumor resembling the tall cell variant of papillary thyroid carcinoma: report of 4 cases with evidence of malignant potential. Int $\mathbf{J}$ Surg Pathol. 2007;15:14-9.

6. Cameselle-Teijeiro J, Abdulkader I, Barreiro-Morandeira F, et al. Breast tumor resembling the tall cell variant of papillary thyroid carcinoma: a case report. Int J Surg Pathol. 2006;14:79-84.

7. Chang SY, Fleiszer DM, Mesurolle B, et al. Breast tumor resembling the tall cell variant of papillary thyroid carcinoma. Breast J. 2009;15:531-5.

8. Colella R, Guerriero A, Giansanti M, et al. An additional case of breast tumor resembling the tall cell variant of papillary thyroid carcinoma. Int J Surg Pathol. 2015;23:217-20.

9. Bhargava R, Florea AV, Pelmus M, et al. Breast tumor resembling tall cell variant of papillary thyroid carcinoma: a solid papillary neoplasm with characteristic immunohistochemical profile and few recurrent mutations. Am J Clin Pathol. 2017;147:399-410.

10. Chiang S, Weigelt B, Wen $\mathrm{H}-\mathrm{C}$, et al. IDH2 mutations define a unique subtype of breast cancer with altered nuclear polarity. Cancer Res. 2016;76:7118-29.

11. Masood S, Davis C, Kubik MJ. Changing the term "breast tumor resembling the tall cell variant of papillary thyroid carcinoma" to "tall cell variant of papillary breast carcinoma". Adv Anat Pathol. 2012;19:108-10.

12. Foschini MP, Asioli S, Foreid S, et al. Solid papillary breast carcinomas resembling the tall cell variant of papillary thyroid neoplasms: a unique invasive tumor with indolent behavior. Am J Surg Pathol. 2017;41:887-95.

13. Goff L, Trapnell C. cummeRbund. Bioconductor; 2017.

14. Trapnell C, Roberts A, Goff L, et al. Differential gene and transcript expression analysis of RNA-seq experiments with TopHat and Cufflinks. Nat Protoc. 2012;7:562-78.

15. Gendoo DMA, Ratanasirigulchai N, Schröder MS, et al. Genefu: an R/Bioconductor package for computation of gene expressionbased signatures in breast cancer. Bioinforma Oxf Engl. 2016;32: 1097-9.

16. Parker JS, Mullins M, Cheang MCU, et al. Supervised risk predictor of breast cancer based on intrinsic subtypes. J Clin Oncol. 2009;27:1160-7.

17. Lau SK, Luthringer DJ, Eisen RN. Thyroid transcription factor-1: a review. Appl Immunohistochem Mol Morphol. 2002;10: 97-102.

18. Villar-Taibo R, Peteiro-González D, Cabezas-Agrícola JM, et al. Aggressiveness of the tall cell variant of papillary thyroid carcinoma is independent of the tumor size and patient age. Oncol Lett. 2017;13:3501-7.

19. Cancer Genome Atlas Research Network. Integrated genomic characterization of papillary thyroid carcinoma. Cell. 2014;159: 676-90.

20. Filmus J, Capurro M, Rast J. Glypicans. Genome Biol. 2008;9:224.

21. Matsuda K, Maruyama H, Guo F, et al. Glypican-1 is overexpressed in human breast cancer and modulates the mitogenic effects of multiple heparin-binding growth factors in breast cancer cells. Cancer Res. 2001;61:5562-9. 
22. Fernández-Vega I, García O, Crespo A, et al. Specific genes involved in synthesis and editing of heparan sulfate proteoglycans show altered expression patterns in breast cancer. BMC Cancer. 2013;13:24.

23. Topczewski J, Sepich DS, Myers DC, et al. The zebrafish glypican knypek controls cell polarity during gastrulation movements of convergent extension. Dev Cell. 2001;1:251-64.

24. Rakha EA, Ahmed MA, Ellis IO. Papillary carcinoma of the breast: diagnostic agreement and management implications. Histopathology. 2016;69:862-70.

25. Lugli A, Forster Y, Haas P, et al. Calretinin expression in human normal and neoplastic tissues: a tissue microarray analysis on 5233 tissue samples. Hum Pathol. 2003;34:994-1000.

26. Taliano RJ, Lu S, Singh K, et al. Calretinin expression in highgrade invasive ductal carcinoma of the breast is associated with basal-like subtype and unfavorable prognosis. Hum Pathol. 2013;44:2743-50.

27. Farrag MS, El-Karef AA, Amin MM, et al. Calretinin expression as a reliable prognostic marker in different molecular subtypes of breast carcinoma. Indian $\mathrm{J}$ Pathol Microbiol. 2017;60:8-14.

28. Micello D, Bossi A, Marando A, et al. Expression of calretinin in high-grade hormone receptor-negative invasive breast carcinomas: correlation with histological and molecular subtypes. Virchows Arch Int J Pathol. 2017;471:13-21.

29. Lakhani S, Ellis IO, Schnitt SJ, et al. WHO Classification of Tumours of the Breast. Lyon: IARC; 2012. .

30. MacGrogan G, Tavassoli FA. Central atypical papillomas of the breast: a clinicopathological study of 119 cases. Virchows Arch Int J Pathol. 2003;443:609-17.

31. Yan H, Parsons DW, Jin G, et al. IDH1 and IDH2 mutations in gliomas. N Engl J Med. 2009;360:765-73.

32. Medeiros BC, Fathi AT, DiNardo CD, et al. Isocitrate dehydrogenase mutations in myeloid malignancies. Leukemia. 2017;31:272-81.

33. Borger DR, Zhu AX. IDH mutations: new genetic signatures in cholangiocarcinoma and therapeutic implications. Expert Rev Anticancer Ther. 2012;12:543-6.

34. Kato Kaneko M, Liu X, Oki H, et al. Isocitrate dehydrogenase mutation is frequently observed in giant cell tumor of bone. Cancer Sci. 2014;105:744-8.

35. Amary MF, Bacsi K, Maggiani F, et al. IDH1 and IDH2 mutations are frequent events in central chondrosarcoma and central and periosteal chondromas but not in other mesenchymal tumours. J Pathol. 2011;224:334-43.
36. Liu X, Kato Y, Kaneko MK, et al. Isocitrate dehydrogenase 2 mutation is a frequent event in osteosarcoma detected by a multi-specific monoclonal antibody MsMab-1. Cancer Med. 2013;2:803-14.

37. Clark O, Yen K, Mellinghoff IK. Molecular pathways: isocitrate dehydrogenase mutations in cancer. Clin Cancer Res. 2016;22: 1837-42.

38. Lu C, Ward PS, Kapoor GS, et al. IDH mutation impairs histone demethylation and results in a block to cell differentiation. Nature. 2012;483:474-8.

39. Figueroa ME, Abdel-Wahab O, Lu C, et al. Leukemic IDH1 and IDH2 mutations result in a hypermethylation phenotype, disrupt TET2 function, and impair hematopoietic differentiation. Cancer Cell. 2010;18:553-67.

40. Kato Kaneko M, Ogasawara S, Kato Y. Establishment of a multispecific monoclonal antibody MsMab-1 recognizing both IDH1 and IDH2 mutations. Tohoku J Exp Med. 2013;230:103-9.

41. Salameh A, Lee AK, Cardó-Vila M, et al. PRUNE2 is a human prostate cancer suppressor regulated by the intronic long noncoding RNA PCA3. Proc Natl Acad Sci USA. 2015;112:8403-8.

42. Yu W, McPherson JR, Stevenson M, et al. Whole-exome sequencing studies of parathyroid carcinomas reveal novel PRUNE2 mutations, distinctive mutational spectra related to APOBEC-catalyzed DNA mutagenesis and mutational enrichment in kinases associated with cell migration and invasion. $\mathrm{J}$ Clin Endocrinol Metab. 2015;100:E360-4.

43. Soh UJK, Low BC. BNIP2 extra long inhibits RhoA and cellular transformation by Lbc RhoGEF via its BCH domain. J Cell Sci. 2008;121:1739-49.

44. Jacob T, Gray JW, Troxell M, et al. Multiplexed imaging reveals heterogeneity of PI3K/MAPK network signaling in breast lesions of known PIK3CA genotype. Breast Cancer Res Treat. 2016;159: 575-83.

45. Troxell ML, Levine J, Beadling C, et al. High prevalence of PIK3CA/AKT pathway mutations in papillary neoplasms of the breast. Mod Pathol. 2010;23:27-37.

46. Nielsen TO, Parker JS, Leung S, et al. A comparison of PAM50 intrinsic subtyping with immunohistochemistry and clinical prognostic factors in tamoxifen-treated estrogen receptor-positive breast cancer. Clin Cancer Res. 2010;16:5222-32.

47. Rakha EA, Tan DSP, Foulkes WD, et al. Are triple-negative tumours and basal-like breast cancer synonymous? Breast Cancer Res. 2007;9:404.

48. DiNardo CD, Stone RM, Medeiros BC. Novel therapeutics in acute myeloid leukemia. Am Soc Clin Oncol Educ Book. 2017;37:495-503. 